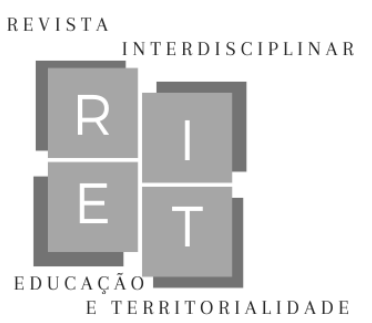

\title{
A percepção das professoras e dos professores sobre a avaliação municipal: o caso do SMAEF
}

\author{
The perception of teachers about municipal evaluation: the case of SMAEF
}

La percepción de maestros sobre la evaluación municipal: el caso de SMAEF

\author{
Raphaell Moreira Martins \\ Instituto Federal de Educação, Ciência e Tecnologia do Ceará. \\ Baturité, Ceara, Brasil. \\ E-mail: raphaell.martins@ifce.edu.br \\ ORCID: https://orcid.org/0000-0001-6988-7795 \\ Pedro Henrique Silvestre Nogueira \\ Faculdade Vale do Jaguaribe (FVJ) \\ Aracati, Ceará, BrasilE-mail: pedro.silvestre@fvj.br \\ ORCID: https://orcid.org/0000-0002-1533-9387
}

Antonio Carlos de Souza

Escola Doutor José Martins de Santiago Russas Russas, Ceara, Brasil.

E-mail: adesousa491@gmail.com

ORCID: https://orcid.org/0000-0002-8650-794X

Resumo: $\mathrm{O}$ ato de avaliar é cada vez mais entendido como um dos principais parâmetros para se pensar a elaboração de políticas públicas e organização do trabalho docente. Este artigo tem como objetivo analisar a percepção das professoras e dos professores sobre uma avaliação municipal, doravante Sistema Municipal de Avaliação do Ensino Fundamental (SMAEF), levando em consideração suas implicações na autonomia docente. A pesquisa é de cunho qualitativo e classificada como um estudo de caso descritivo. Foi ambientada no município de Russas-CE, com 57 docentes. Utilizou-se como instrumento de mapeamento de dados um questionário eletrônico semiestruturado. No que se refere aos principais resultados encontrados, identificamos que a periodicidade do SMAEF se expressa muito mais como um fiscal do cumprimento da organização curricular vigente, do que, um parâmetro formativo da aprendizagem das alunas e dos alunos. O método de comunicação dos resultados nesta avaliação é mobilizado pela gestão escolar, no sentido de identificar os potenciais erros do corpo docente e construir um cenário de desconfiança da capacidade profissional do grupo. Os professores apresentaram insatisfação com o prestígio de algumas áreas do conhecimento, em detrimento de outras. Chegamos às conclusões provisórias que o trabalho docente naquela região é, por extensão, reflexo da política educacional que vem sendo implementada no Ceará. Nesse sentido, apostam vorazmente em avaliações padronizadas, sem se importarem com os resultados adversos por elas produzidos. Palavras-chave: Educação. Avaliação Externa. Autonomia Docente.

RIET- ISSN 2676-0355, Dourados, v. 2, n. 2, p. 368 a 390, jan./jun., 2021 


\section{A percepção das professoras e dos professores sobre a avaliação municipal: o caso do SMAEF}

Abstract: The act of evaluating is increasingly understood as one of the main parameters for thinking about the elaboration of public policies and the organization of teaching work. This article aims to analyze the perception of teachers about a municipal evaluation, henceforth Municipal Elementary Education Evaluation System (SMAEF), taking into account its implications in teacher autonomy. The research is qualitative in nature and classified as a descriptive case study. It was set in the municipality of Russas-CE, with 57 teachers. A semi-structured electronic questionnaire was used as a data mapping instrument. With regard to the main results found, we identified that the periodicity of the SMAEF is expressed much more as a fiscal of compliance with the current curricular organization, than a formative parameter of the students learning. The method of communicating the results in this evaluation is mobilized by school management, in order to identify the potential errors of the teaching staff and build a scenario of distrust of the group's professional capacity. Teachers were dissatisfied with the prestige of some areas of knowledge, to the detriment of others. We have reached the provisional conclusions that the teaching work in that region is, by extension, a reflection of the educational policy that has been implemented in Ceará. In this sense, they voraciously bet on standardized evaluations, regardless of the adverse results produced by them.

Keywords: Education. External Evaluation. Teacher Autonomy.

Resumen: El acto de evaluar se entiende cada vez más como uno de los principales parámetros para pensar en la elaboración de políticas públicas y la organización del trabajo docente. Este artículo tiene como objetivo analizar la percepción de los profesores y profesoras sobre una evaluación municipal, a partir del SMAEF, teniendo en cuenta sus implicaciones en la autonomía del profesorado. La investigación es de carácter cualitativa y clasificada como un caso práctico descriptivo. Fue realizada en el municipio de Russas-CE, con 57 profesores. Se utilizó un cuestionario electrónico semi-estructurado como instrumento de mapeo de datos. En relación a los principales resultados encontrados, identificamos que la periodicidad de la SMAEF se expresa mucho más como una fiscalía sobre el cumplimiento de la organización curricular actual, que como un parámetro formativo del aprendizaje de los alumnos y alumnas. El método de comunicación de los resultados en esta evaluación es coordinado por la dirección de la escuela, con el fin de identificar los posibles errores cometidos por el personal docente y construir un escenario de desconfianza de la capacidad profesional del grupo. Los maestros estaban insatisfechos con el prestigio de algunas áreas del conocimiento, en detrimento de otras. Hemos llegado a las conclusiones provisionales de que la labor docente en esa región es, por extensión, un reflejo de la política educativa que se ha puesto en marcha en Ceará. En este sentido, apuestan vorazmente por evaluaciones estandarizadas, independientemente de los resultados adversos producidos por ellos.

Palabras Clave: Educación. Evaluación Externa. Autonomía del professorado.

Data de recebimento: 04/03/2021

Data de aprovação: 11/06/2021

DOI: $10.30612 /$ riet.v2i2.14240

\section{Introdução}

$\mathrm{O}$ ato de avaliar, cada vez mais entendido como um dos principais parâmetros para se pensar a elaboração de políticas públicas e organização do trabalho docente, deve ser uma pauta permanente nos debates acerca da Educação, pois seus resultados têm colaborado para

RIET- ISSN 2676-0355, Dourados, v. 2, n. 2, p. 368 a 390, jan./jun., 2021 


\section{A percepção das professoras e dos professores sobre a avaliação municipal: o caso do SMAEF}

o "sucesso acadêmico-profissional" de uma minoria em detrimento do "insucesso" de tantos outros e tantas outras, sobretudo, alunos e alunas oriundos das escolas públicas do país.

No caso do Brasil, a avaliação educacional "passa a ser objeto de intenso debate, tanto nos meios acadêmicos, como nos altos escalões das instâncias do governo (LIMA, 2012, p. 42)". Foi a partir da década de 1980, que o modelo de avaliação adotado hoje, marcado pelo Estado controlador, iniciou-se ancorado na lógica das avaliações externas e de larga escala. Exigências de organismos internacionais, que têm provocado a redefinição de sistemas educacionais e do currículo escolar de países periféricos (LEHER, 1999).

Um exemplo comum dessas transformações ocorridas na América Latina foi a implementação dos modelos de accountability (responsabilização) que ocasionou dentre outras deliberações, a descentralização da Educação, definições de padrões educacionais, premiações e/ou penalidades aos agentes escolares e criações de avaliações externas estandardizadas (AFONSO, 2016).

Este último, configura-se como objeto do presente estudo e, por essa razão, se faz necessário compreender o que classificamos como avaliações externas e de larga escala. Destarte, compreendemos a avaliação externa como sendo

Toda avaliação que é realizada ou idealizada por órgãos externos à escola. Ela é pensada e montada fora da escola, mesmo que seja aplicada pelos professores da própria instituição de ensino, podendo ser de larga escala ou não. Ela receberá o nome de avaliação de larga escala se for aplicada num sistema de ensino inteiro, podendo ser da esfera municipal, estadual ou federal (SANTANA, 2018, p. 38).

Dentre as principais avaliações em larga escala existentes no Brasil, podemos citar o caso emblemático do Sistema de Avaliação da Educação Básica (SAEB), que visa diagnosticar na educação básica os fatores socioeconômicos e técnicos que podem interferir no desempenho do estudante. As médias do desempenho no sistema SAEB subsidiam o cálculo do Índice de Desenvolvimento da Educação Básica (IDEB). De posse desses resultados, posteriormente, são utilizados para traçar metas em prol da qualidade dos sistemas de ensino (BRASIL, 2020).

Tendo o entendimento deste sistema de avaliações de esfera nacional, faz-se urgente elaborar alguns pontos sobre as avaliações estaduais e municipais. Para esse objetivo, é possível mencionar as experiências realizadas no Estado do Ceará, que possui sua própria avaliação, o Sistema Permanente de Avaliação da Educação Básica do Ceará (SPAECE).

RIET- ISSN 2676-0355, Dourados, v. 2, n. 2, p. 368 a 390, jan./jun., 2021 


\section{A percepção das professoras e dos professores sobre a avaliação municipal: o caso do SMAEF}

Em síntese, o SPAECE, implementado pela Secretaria da Educação do Ceará (SEDUC), tem como objetivo promover um ensino de qualidade e equânime para todos os alunos e todas as alunas da rede pública do estado. Assim como acontece no IDEB, o conjunto de informações colhidas pelo SPAECE permite diagnosticar a qualidade da educação pública do Ceará (CEARÁ, 2018).

Porém, nos últimos anos, o SPAECE vem sendo adotado como dispositivo político por parte de vários governantes como uma suposta comprovação de sucesso da educação pública cearense. Ressaltamos que a apropriação política das avaliações de larga escala serem produtos para contestação de agentes políticos, não é novidade, e ocorre até com certa frequência em determinados contextos e arenas políticas.

Essa postura de politizar as avaliações externas, como o SPAECE, promove dois grandes impactos, um microestrutural e outro macroestrutural. A dimensão microestrutural ocorre na movimentação em que as escolas promovem para garantir o melhor resultado nestas avaliações, que não necessariamente estão vinculadas aos compromissos pedagógicos e de qualificação do ensino e da aprendizagem. Mas, em uma tentativa de sobrevivência de certas estruturas de núcleos gestores quando o resultado é satisfatório e a abertura de espaço para assédios e perseguições que ocorrem com os resultados negativos.

No plano macroestrutural, encontramos a possibilidade de governantes e profissionais do alto escalão das redes de ensino capitalizarem benefícios próprios que também não estão diretamente relacionados aos princípios do desenvolvimento educacional, como, por exemplo, abrir trincheiras para empresas educacionais venderem seus produtos (formação continuada, livros didáticos, plataformas educacionais interativas, entre outros) para as redes de ensino quando o resultado não é alcançado.

No entanto, com relação às avaliações municipais, faz-se necessário mencionar alguns pontos fundantes, nos quais sem estes elementos reflexivos cairíamos no risco da superficialidade pela qual vem sendo tratado essa discussão. A primeira observação a se fazer é lembrar que, como já exposto, a década de 1980 proporcionou no país inúmeras transformações na esfera municipal, permitindo os municípios terem maior autonomia e responsabilidade com os recursos públicos (DE SOUZA CASTRO e DE SOUSA, 2018).

É nesse contexto, associado ao discurso da qualidade e o alcance de melhores desempenhos nas avaliações de maior expressão, como SPAECE e IDEB, que são formuladas as avaliações municipais. Uma visão simplória sobre o complexo da Educação,

RIET- ISSN 2676-0355, Dourados, v. 2, n. 2, p. 368 a 390, jan./jun., 2021 


\section{A percepção das professoras e dos professores sobre a avaliação municipal: o caso do SMAEF}

que visa apenas a relação linear, baseado na lógica bancária (FREIRE, 2013) entre o professor-aluno, desvaloriza os conteúdos regionais, torna invisível o saber-coletivo já que estas avaliações individualizam a aprendizagem, e que de forma perigosa, rotulam escolas que não tiveram o desempenho desejado.

\section{Desenvolvimento}

\section{Apontamentos sobre o Sistema Municipal de Avaliação do Ensino Fundamental (SMAEF)}

Para um melhor entendimento da avaliação municipal, investigada neste estudo, ou seja, o SMAEF, é imprescindível mencionarmos algumas ponderações relevantes. Com base em seu site oficial ${ }^{1}$, notamos que o SMAEF é uma avaliação idealizada pela Assessoria e Gestão Educacional (AGE), uma extensão do Grupo Empresarial You Educ, criado em 2009, sediado em Brasília-DF e que realiza algumas atividades, tais como: soluções educacionais, organizacionais e tecnológicas; gestão escolar e educação corporativa.

Na perspectiva de Costa (2011), o avanço das políticas neoliberais, permitiu um aumento nos lucros de grupos educacionais que se expandem a cada dia. Assim, questões como a qualidade do ensino, pesquisa e extensão, passam a assumir exclusivamente um caráter mercantil. "No contexto do capitalismo financeiro, a Educação deixou de ser direito social e foi transformada em serviço altamente lucrativo" (CHAVES, 2019, p. 66).

A respeito do município de Russas, localizado no estado do Ceará, observamos que este não é o único município cearense a adotar o SMAEF como principal instrumento responsável por avaliar e classificar os níveis de qualidade do ensino e a aprendizagem das/dos estudantes. Esta avaliação já se faz presente em outros seis municípios do estado supracitado, a saber: Maranguape, Pacatuba, Itaitinga, Aratuba, Acarape e Quixeré.

De acordo com as Diretrizes da Educação Municipal 2017-2020 do município de Russas, as disciplinas que contam com o SMAEF são: Língua Portuguesa, Matemática, História, Geografia e Ciências (RUSSAS, 2017). Quanto à sua dinâmica, é expresso em suas diretrizes que:

É uma avaliação que acontece de forma periódica fundamentada nos descritores da Prova Brasil e SPAECE. Diante dos relatórios disponibilizados na plataforma De Olho na Rede, é possível diagnosticar a qualidade da educação municipal de Russas, por meio dos resultados por

\footnotetext{
${ }^{1}$ https://youeduc.com.br/ 372

RIET- ISSN 2676-0355, Dourados, v. 2, n. 2, p. 368 a 390, jan./jun., 2021 


\title{
A percepção das professoras e dos professores sobre a avaliação municipal: o caso do SMAEF
}

aluno, escola, descritores, gráficos por padrão de desempenho e ranking dos resultados. Os resultados apresentados são acompanhados sistematicamente pela Secretaria Municipal da Educação, com o objetivo de promover intervenções e efetivar ações orientadas para a melhoria do ensino (RUSSAS, 2017, p.45).

Analisando criteriosamente o trecho acima, percebemos que o SMAEF tem sua periodicidade demarcada como sendo uma avaliação bastante presente no cotidiano das escolas, pois acontece em todos os bimestres, a partir dos $2^{\circ}$ anos do ensino fundamental (anos iniciais). A respeito desta dinâmica, acreditamos que o ensino de Russas se torna mais um refém das avaliações. É só pensar brevemente na quantidade de propostas avaliativas a que os alunos e as alunas, tradicionalmente, estão submetidos.

Como visto o SMAEF também se fundamenta nos descritores da Prova Brasil e SPAECE, sendo que as aulas, nesse sentido, correm o risco de tornarem-se uma mera preparação para as avaliações de maior expressão, que se tornam, neste caso, uma verdadeira matriz de referência (CUNHA et al, 2020).

De acordo com Machado (2019) o município possui um sistema próprio de premiação, denominado de Gratificação de Incentivo ao Desempenho (GID), que contempla com um prêmio em dinheiro, no valor de um $14^{\circ}$ salário, os profissionais das três escolas que tiverem melhor desempenho durante o ano letivo, incluindo o SMAEF.

Julgamos que talvez essa classificação aconteça de forma desigual. Pois, pensando na realidade de boa parte das escolas públicas brasileiras, são aquelas que sofrem por falta de recursos humanos e financeiros, que têm sérias dificuldades de promover o diálogo necessário com as famílias e, na maioria das vezes acolhem estudantes considerados "fora de faixa", geralmente remanejados de outras escolas, seja por indisciplina ou notas baixas.

Pensando nessa realidade, tornam-se limitadas as possibilidades de angariar um desempenho adequado neste formato de avaliação. Dada estas condições, concordamos com Nosella (2010) ao pontuar que:

\begin{abstract}
A cultura do desempenho, delega ao mercado a elaboração de modelos gestores educacionais a serem desempenhados e responsabiliza a escola pelos medíocres resultados, evidenciando assim um indisfarçável antihumanismo pedagógico (NOSELLA, 2010 p. 43).
\end{abstract}

No que se refere ao discurso da qualidade, mencionado no PEM de Russas, temos que levar em consideração que tal perspectiva tem se tornado uma verdadeira armadilha para os docentes, já que visa ajustar o que se passa na escola com o modelo de gerenciamento 


\title{
A percepção das professoras e dos professores sobre a avaliação municipal: o caso do SMAEF
}

empresarial, pautado na lógica da produtividade para o alcance de metas formuladas pelos que "pensam" a escola sem conhecer a realidade de uma sala de aula. Assim, esse discurso

\begin{abstract}
Além de servir para legitimar os regimes de verdade dos discursos oficiais que advogam a favor da transparência e do controle social sobre os resultados das avaliações nacionais, produz efeitos de vigilância sobre o trabalho dos professores e acirram disputas entre as instituições e os sujeitos, fortalecendo as lógicas empresariais da concorrência e da competitividade na gestão da educação (VOSS; GARCIA, 2014, p. 392).
\end{abstract}

Com base no que foi explicitado, formulamos, então, a seguinte problemática: Qual a percepção das professoras e dos professores a respeito da avaliação do município, o SMAEF? A partir desta, construímos as questões secundárias, a saber: quais as implicações do SMAEF no cotidiano das escolas, evidenciando aspectos de sua periodização e preparação? Quais os aspectos positivos e negativos para a Educação de Russas?

Sendo assim, o objetivo primário deste estudo se constitui em analisar a percepção das professoras e dos professores sobre o SMAEF, levando em consideração suas implicações na autonomia docente. Como objetivos específicos elencamos os seguintes: compreender as implicações do SMAEF no cotidiano das professoras e dos professores; identificar os aspectos positivos e negativos para a Educação de Russas.

O estudo torna-se relevante na medida em que visa oportunizar o debate sobre avaliação a partir da ótica de quem convive diretamente com elas no "chão da escola pública”, e que, salvo raras exceções, se reconhecem nos resultados divulgados nas diversas mídias, o que já se tornou uma práxis. A respeito desta complexidade, autora clássica Jussara Hoffmann (1994) salienta que os professores nem mesmo são conscientes desta lógica reprodutivista em seu fazer docente.

\section{Itinerário metodológico}

\section{Tipo de estudo}

Por descrever e analisar uma unidade social, levando em conta suas variadas dimensões no curso de sua dinâmica natural, permitindo-nos, ainda, compreender como um determinado fenômeno surge, se desenvolve e evolui, esta pesquisa classifica-se como um estudo de caso descritivo. Para Meirinhos e Osório (2010), esse tipo de estudo representa uma descrição completa de um fenômeno inserido no seu próprio contexto. Isto posto, a preferência pelo estudo de caso se deu pelo fato de que: 


\section{A percepção das professoras e dos professores sobre a avaliação municipal: o caso do SMAEF}

Os estudos de caso podem ser instrumentos valiosos, pois o contato direto e prolongado do pesquisador com os eventos e situações investigadas possibilita descrever ações e comportamentos, captar significados, analisar interações, compreender e interpretar linguagens, estudar representações, sem desvinculá-los do contexto e das circunstâncias especiais em que se manifestam (ANDRÉ, 2013, p. 97).

Metodologicamente, dois fatores nos levaram a categorizar esta proposta como um estudo de caso, a saber: Dentre os municípios que compõem a Coordenadoria Regional de Desenvolvimento da Educação ${ }^{2}$ (CREDE-10), Russas é o único a contar com uma avaliação municipal. Outro dado é que o desempenho de suas escolas nas últimas edições do IDEB superou as médias do Ceará e do Brasil, classificando a Educação russana como a melhor da região (RUSSAS, 2017).

\section{Abordagem da pesquisa}

Daremos preferência pela abordagem de natureza qualitativa por possibilitar a interação dos pesquisadores com o material empírico coletado, bem como sua interpretação no sentido de processo e não produto. Orientada à luz desse entendimento, André (2013) reforça que a abordagem qualitativa enuncia o conhecimento como um processo socialmente construído pelos sujeitos históricos em suas formas de interações cotidianas na realidade, transformando-a ao passo que por ela também são transformados.

\section{Descrição de Russas (cenário da pesquisa)}

Fundada em 1938, Russas é um município cearense localizado na mesorregião do Jaguaribe. Conforme com os dados do Instituto Brasileiro de Geografia e Estatística (IBGE, 2020), o município possui uma população estimada em 78.882 habitantes, sendo que $73,3 \%$ desta estão distribuídas na zona urbana (Sede). Por sua vez, o PME de Russas (2015) afirma que o município apresenta um contingente de 47 unidades escolares, entre os três níveis de ensino, sendo que 37 ofertam matrículas para o ensino fundamental, que abriga um quantitativo de 9.106 educandos.

\footnotetext{
${ }^{2}$ Em meio aos processos de descentralização, a todo vapor nos anos de 1990, o Governo Estadual implementou em 1996 a regionalização do Ceará, dividindo-o em Regiões Administrativas. Neste período foram criados 21 Centros Regionais de Desenvolvimento da Educação por meio do Decreto No 24.274, de 22/11/1996, possuindo como principal finalidade: exercer, em nível regional, as ações de planejamento, cooperação técnica e financeira, orientação normativa, mobilização, articulação e integração institucional (CEARÁ, 2012).
}

RIET- ISSN 2676-0355, Dourados, v. 2, n. 2, p. 368 a 390, jan./jun., 2021 


\section{A percepção das professoras e dos professores sobre a avaliação municipal: o caso do SMAEF}

\section{Colaboradores da pesquisa}

Os colaboradores e as colaboradoras da pesquisa foram 57 docentes, sendo que 52 se identificaram como professores efetivos e 4 na condição de professor temporário, sendo que 24 professores atuam somente na zona urbana do município, 25 na zona rural e apenas 8 professores atuam nas duas condições. Dentre os professores, 20 relataram terem maior carga horária nos anos iniciais do ensino fundamental, 33 nos anos finais e apenas 4 atuam nos dois níveis de ensino. A maioria dos professores também relataram ter de 3 a 7 anos de experiência docente. Seguindo a lógica empreendida por Huberman (1995) acerca do ciclo de vida profissional, o grupo investigado está em sua maioria concluindo a fase de entrada na carreira docente e iniciando a etapa de estabilização e consolidação do repertório teóricometodológico, estando mais seguros de sua função docente.

\section{Critérios de inclusão e exclusão}

Para contemplar a maior quantidade de participações, foram elencados como critérios de inclusão: atuar nas escolas do município na condição de professor efetivo, temporário ou cumprir o regime de estágio probatório; concordar com o termo de consentimento expresso no instrumento de coleta de dados. Somam-se como critérios de exclusão: atuar em outro nível de ensino que não seja o ensino fundamental; optar por desistir da pesquisa a qualquer momento.

\section{Instrumento de coleta de dados}

Devido ao momento da pandemia por COVID-19, tornou-se inviável qualquer possibilidade de contato presencial com os professores e as professoras do município, já que o período da coleta se deu entre os meses de maio e julho de 2020. Portanto, utilizamos como instrumento de mapeamento de dados um questionário eletrônico semiestruturado, composto por quatro seções, do tipo survey, via google forms.

A primeira seção foi elaborada com o objetivo de traçar o perfil dos colaboradores. Portanto, foi solicitado que eles informassem algumas características como a idade, nível de escolaridade, tempo de experiência docente, disciplina com que atua, dentre outros. Nas seções seguintes, adentramos na dinâmica do SMAEF. Foram elaboradas perguntas sobre sua especificidade, questões relacionadas à autonomia, valorização e trabalho docente e, por

RIET-ISSN 2676-0355, Dourados, v. 2, n. 2, p. 368 a 390, jan./jun., 2021 


\section{A percepção das professoras e dos professores sobre a avaliação municipal: o caso do SMAEF}

fim, solicitamos aos colaboradores que apontassem os aspectos negativos e positivos do SMAEF para a Educação do município.

Com o intuito de melhoria desse instrumento, submetemos a um grupo de pré-teste, e após criteriosas análises, chegamos à versão final ${ }^{3}$. Segundo (CARLOMAGNO, (2018, p. 50), utilizando métodos e técnicas de forma correta os "surveys online são um método ainda a ser empreendido, que oferece alto potencial e oportunidades".

\section{Análise dos dados}

O momento da análise dos dados nada mais é do que a interpretação dos artefatos obtidos durante o processo de investigação. Configura-se, portanto, na visão de Minayo (1994) um olhar atento para os dados da pesquisa. Para tanto, validar-nos-emos da análise de conteúdo como método de investigação, que, em face dos problemas cada vez mais diversificados, possibilita-nos conduzir às descrições sistemáticas, sendo quantitativas ou qualitativas, ajuda-nos a reinterpretar as mensagens e a alcançar uma compreensão de seus significados em um nível que ultrapassa uma leitura comum (MORAES, 1999).

\section{Aspectos éticos}

Mencionamos que este estudo atendeu a Resolução n ${ }^{\circ}$ 510/2016, que discorre sobre pesquisas em Ciências Humanas e Sociais, considerando-se o que descreve o inciso "VII pesquisa que objetiva o aprofundamento teórico de situações que emergem espontânea e contingencialmente na prática profissional, desde que não revelem dados que possam identificar o sujeito" (CONSELHO NACIONAL DE SAÚDE, 2016, p. 2).

\section{Resultados e discussões}

\section{Questões específicas sobre o SMAEF}

É salutar destacar que o trabalho com a percepção docente envolve intensos traços de subjetividade. Nesta esteira, tem sido uma preocupação secundária ou até mesmo ignorada na formação inicial, continuada e no cotidiano escolar (ROSSATO, MATOS e PAULA, 2018). Por sua vez, a percepção das professoras e dos professores, é resultado de

\footnotetext{
${ }^{3}$ Link de acesso ao questionário: https://docs.google.com/forms/d/e/1FAIpQLSfHVAm71JcYpwRYhF3JARkFzeKoIo695T8KYM_1rTifw$\underline{\mathrm{XNOg} / \text { viewform }}$
} 


\section{A percepção das professoras e dos professores sobre a avaliação municipal: o caso do SMAEF}

suas complexidades relacionais vivenciadas em suas trajetórias, estando intrinsecamente ligada às suas identidades, suas maneiras de verem e interpretarem o mundo em seu entorno.

Adentramos ao momento de apresentação dos principais achados. Como já mencionado, a primeira seção do questionário objetivava debruçar-se sobre as questões específicas do SMAEF no cotidiano dos professores e das professoras, como apresentado sinteticamente no quadro a seguir:

Quadro 1 - Perguntas específicas sobre o SMAEF

\begin{tabular}{|c|c|c|}
\hline \multicolumn{3}{|c|}{ Qual sua percepção quanto a periodicidade do SMAEF (a cada bimestre)? } \\
\hline & $\mathbf{N}$ & $\%$ \\
\hline Baixa & 02 & 3,5 \\
\hline Razoável & 31 & 54,4 \\
\hline Alta & 18 & 31,6 \\
\hline Muito alta & 06 & 10,5 \\
\hline \multicolumn{3}{|c|}{$\begin{array}{l}\text { Em sua percepção, a atual periodicidade do SMAEF favorece um bom desenvolvimento do } \\
\text { trabalho docente? }\end{array}$} \\
\hline & $\mathbf{N}$ & $\%$ \\
\hline $\operatorname{Sim}$ & 20 & 35,1 \\
\hline Não & 35 & 61,4 \\
\hline Desconheço & 2 & 3,5 \\
\hline \multicolumn{3}{|c|}{$\begin{array}{l}\text { A utilização do livro didático ou outros recursos da escola (biblioteca e laboratório, por exemplo) } \\
\text { é diminuída durante o período de preparação para as avaliações do SMAEF? }\end{array}$} \\
\hline & $\mathbf{N}$ & $\%$ \\
\hline Nunca & 03 & 5,3 \\
\hline Raramente & 09 & 15,8 \\
\hline Razoavelmente & 17 & 29,8 \\
\hline Com muita frequência & 15 & 26,3 \\
\hline Sempre & 13 & 22,8 \\
\hline
\end{tabular}

Fonte: Elaboração própria, 2021, p. 13

A pesquisa aqui descrita mostrou que a aplicação do SMAEF se dá bimestralmente. Isso posto, perguntamos aos docentes se esse intervalo de tempo é suficiente para que os "conteúdos" sejam trabalhados? Logo, deparamo-nos com os seguintes dados: no quadro acima, 31 participantes consideram a atual periodicidade razoável. Por outro lado, apenas 2 378

RIET-ISSN 2676-0355, Dourados, v. 2, n. 2, p. 368 a 390, jan./jun., 2021 


\section{A percepção das professoras e dos professores sobre a avaliação municipal: o caso do SMAEF}

participantes, especificamente, revelam que essa periodicidade é baixa. Para compreender melhor essa questão, realizamos a seguinte reflexão.

Em nossa perspectiva, o fato de o SMAEF ser implementado a cada bimestre se expressa muito mais como um fiscal do cumprimento da organização curricular vigente, do que, um parâmetro formativo da aprendizagem das alunas e dos alunos. O ponto fulcral desta análise incorre do reconhecimento da inexistência do tempo pedagógico para se apropriar de tais resultados e amadurecer colaborativamente de iniciativas exequíveis para enfrentar problemas em resultados negativos, como também, observar os atos que favoreceram um resultado satisfatório.

A atenção que desejamos levantar ocorre da seguinte forma, se considerarmos que o acesso tematizado do conhecimento ocorre por meio de um ato de significativa complexidade, que exige um aprofundamento progressivo de suas Unidades Temáticas e respectivos objetos de conhecimento (MARTINS, 2020), evoluindo em um movimento espiralado que deveria está ancorado com os grandes temas sociais, e principalmente em uma proposta de trabalho não hierarquizada por razões do contexto de ensino, a relação que a turma faz com este saber compartilhado e as condições objetivas de trabalho das professoras e dos professores.

O SMAEF sendo implementado a cada dois meses, ao invés de promover um diálogo com esta concepção de aprendizagem citada na passagem anterior, favorece uma atração fatal para o caminho mais curto, produzir estratégias que promovam o máximo de condições de se obter melhores resultados nesta avaliação. Essa percepção fica clara, tendo em vista que os professores e as professoras precisam resolver sua situação profissional, e uma dessas condições é garantir que sua escola logre êxito no SMAEF.

Esta contradição, pode ser percebida quando nos deparamos com 35 respostas negativas ao questionamento: Em sua percepção, a atual periodicidade do SMAEF favorece um bom desenvolvimento do trabalho docente? Se no quadro anterior temos uma porcentagem significativa para a "razoabilidade" da periodicidade em análise, qual motivo os influenciou para tamanha negatividade?

Ao questionamento "A utilização do livro didático ou outros recursos da escola (biblioteca, laboratório, por exemplo) é diminuída durante o período de preparação para as avaliações do SMAEF?", deparamo-nos, novamente, com a alternativa "razoável” como 


\section{A percepção das professoras e dos professores sobre a avaliação municipal: o caso do SMAEF}

mais marcada, computando 17 respostas. Em seguida a opção "com muita frequência" foi mencionada pelos docentes 15 vezes.

Essa característica de ruptura do método de trabalho pedagógico com vista a acomodação da lógica avaliativa do SMAEF, pode gerar vários transtornos para a trajetória escolar das alunas e dos alunos no tratamento com as práticas avaliativas, tais como: na dimensão pedagógica, compreender que a avaliação se resume a centralizar a atenção nos exames. Na dimensão psicológica, assumir uma personalidade submissa, já que neste tipo de avaliação, as/os estudantes possuem pouca participação na sua constituição e elaboração. Na dimensão sociológica, desenvolve uma postura de naturalidade perante a seletividade social (HOFFMANN, 2003; LUCKESI, 1996).

Nesta postura analisamos a educação bancária (FREIRE, 2013) com todo o seu vigor. Em que a única margem da ação que se oferece às educandas e os educandos é a de receberem os depósitos, guardá-los e arquivá-los. Margem para serem colecionadores ou fixadores das coisas que arquivam. Por isso, esse modelo de acompanhamento do ensino e da aprendizagem por avaliação de larga escala não serve como parâmetro da qualidade do ensino. Seus tentáculos sobre a rede de ensino são tão fortes, que no final das contas, o que ocorre é um movimento inverso, a rede de ensino trabalhando para avaliar o parâmetro de qualidade do SMAEF.

\section{SMAEF e autonomia docente}

Nesta seção, objetivamos colher das professoras e dos professores, respostas sobre a relação do SMAEF na autonomia docente. Para tanto, elaboramos o segundo quadro a fim de demonstrar com precisão os achados localizados no terceiro bloco de perguntas do questionário.

Quadro 2 - Questões relacionadas ao SMAEF e autonomia docente

\begin{tabular}{|l|c|c|}
\hline $\begin{array}{l}\text { Com relação ao modelo de classificação por ranking, como você classifica atualmente a escola em } \\
\text { que atua? }\end{array}$ & N \\
\hline \multicolumn{1}{|c|}{} \\
\hline Apta a conseguir as primeiras colocações & 17 & 29,8 \\
\hline Apta a conseguir as colocações intermediárias & 36 & 63,2 \\
\hline $\begin{array}{l}\text { Com grandes chances de se localizar entre as últimas } \\
\text { colocações }\end{array}$ & 04 & 07 \\
\hline
\end{tabular}




\begin{tabular}{|c|c|c|}
\hline \multicolumn{3}{|c|}{$\begin{array}{l}\text { Em sua percepção, os resultados apresentados pelo SMAEF durante o ano letivo condizem com a } \\
\text { realidade escolar? }\end{array}$} \\
\hline & $\mathbf{N}$ & $\%$ \\
\hline Concordo plenamente & 00 & 00 \\
\hline Concordo parcialmente & 19 & 33,3 \\
\hline Não tenho conhecimento para opinar & 02 & 3,5 \\
\hline Discordo parcialmente & 25 & 43,9 \\
\hline Discordo plenamente & 11 & 19,3 \\
\hline \multicolumn{3}{|c|}{$\begin{array}{l}\text { Em sua percepção, os procedimentos e métodos adotados para a obtenção de resultados no SMAEF } \\
\text { reduz a autonomia docente? }\end{array}$} \\
\hline & $\mathbf{N}$ & $\%$ \\
\hline Sim & 42 & 73,7 \\
\hline Não & 13 & 22,8 \\
\hline Desconheço & 2 & 3,5 \\
\hline
\end{tabular}

Fonte: Elaboração própria, 2021, p. 16

Diante de tais dados, é inegável que esse tipo de avaliação, com objetivos e finalidades limitantes, subtrai a autonomia docente, além da demasiada cobrança que há sobre esses profissionais da educação. Aliás, em se tratando desta última, tomamos consciência das respostas à seguinte indagação: Com relação ao modelo de classificação por "ranking", como você classifica atualmente a escola em que atua? As respostas foram: 17 professores responderam que suas escolas estavam aptas a conseguirem as primeiras colocações, 36 afirmaram que estariam em colocações intermediárias e 04 docentes afirmaram que correriam o risco de permanecer nas últimas colocações.

A partir de um contexto real, as escolas que alcançarem as piores colocações nos rankings, provavelmente serão as que sofrerão mais perseguições, cortes e, de certo modo, serão invisibilizadas perante o sistema de ensino do qual fazem parte. Recorremos ao professor Luíz Carlos de Freitas para discorrer sobre esta questão relevante. Para ele, é possível a criação de um sistema que monitore o desempenho dos educandos se apropriando de uma avaliação institucional, porém frisa que:

Tal sistema não substituirá a avaliação regular do professor, mas deverá ser independente desta e formulado de maneira que se possa traçar linhas de comparação entre as escolas de uma mesma rede de ensino, sem nenhum propósito de premiação ou punição, voltado exclusivamente para alimentar 


\section{A percepção das professoras e dos professores sobre a avaliação municipal: o caso do SMAEF}

a reflexão no interior do processo de avaliação institucional das escolas" (FREITAS, 2005, p. 930).

Em se tratando de uma análise crítico-reflexiva, o referido quadro, isoladamente, não nos fornece informações suficiente para que façamos tal análise. Contudo, ele se revela bastante necessário ante a pergunta seguinte, cujo questionamento foi "Em sua percepção, os resultados apresentados pelo SMAEF durante o ano letivo condizem com a realidade escolar?"

Observemos que 25 participantes alegam que os resultados não condizem com a realidade da escola, ainda que parcialmente discordado. Temos, também, um total de 11 docentes que discordam plenamente, ou seja, de acordo com esses, os resultados definitivamente não condizem com a realidade das instituições de ensino.

Este dado é de grande valia para nosso estudo, uma crítica muito bem articulada pelas professoras e pelos professores nas escolas ocorre quando os resultados das avaliações externas são compartilhados para a comunidade escolar, geralmente o método de comunicação desses resultados é mobilizado pela gestão escolar, no sentido de identificar os potenciais erros do corpo docente para um cenário de resultado adverso e construir um cenário de desconfiança da capacidade profissional do grupo.

Mesmo sabendo, que durante o ano letivo anterior na maioria das escolas foram construídas iniciativas riquíssimas para a cultura escolar, tais como, eventos científicos, culturais e esportivos. Produção de atividades acadêmicas com a comunidade local. Fortalecimento da formação continuada das professoras e dos professores por meio de acesso a curso de Mestrado e Doutorado.

Esse cuidado deve ser tomado por parte de alguns núcleos gestores que são constantemente cobrados pela Secretaria Municipal de Educação, pois quando o resultado do SMAEF é o principal parâmetro da escola, outras iniciativas que são parte do que denominamos de "vivência escolar", deixam de ter sua importância, pois um exame elaborado baseado em uma matriz de referência, não se aproxima do acolhimento desse tipo de aprendizagem.

Outro aspecto que se relaciona com o que estamos dialogando é saber que um dos maiores problemas da sociedade brasileira é a questão da desigualdade, fica nítido que a Educação sob a égide do Estado, também é marcada pela desigualdade estrutural que assola o país. Sobre esta questão, Bauer, Alavarse e Oliveira (2015) compreendem que essas 


\section{A percepção das professoras e dos professores sobre a avaliação municipal: o caso do SMAEF}

avaliações, de maneira geral, não atentam para outras demandas que as escolas enfrentam cotidianamente, como as necessidades estruturais e sociais dos estudantes. Nesse contexto de rupturas, seus resultados têm sido ineficazes para solucionar ou pelo menos diminuir as desigualdades escolares.

Por fim, fomos mais diretos no tocante à autonomia docente quando resolvemos perguntar aos sujeitos participantes o seguinte: Em sua percepção, os procedimentos e métodos adotados para a obtenção de resultados no SMAEF reduz a autonomia docente? Diante do questionamento 43 professores e professoras afirmaram que sim, enquanto 13 consideram o oposto, que não.

Nos referimos à métodos e técnicas como sendo todas ações empreendidas pelos agentes escolares e secretária de Educação na preparação dos alunos e das alunas à realização das avaliações. Assim compreendemos que, formação continuada, reuniões de colegiado, elaboração de materiais (simulados, atividades de reforço, dentre outros), visitas técnicas, são produtos dessas ações.

Quanto a esses dados, transparece ao professor e a professora a sensação de que não conseguiu aprender o suficiente para se deparar com a realidade escolar. Em tese, as políticas neoliberais do accountability implantadas nas escolas fariam com que as professoras e os professores se tornassem mais comprometidos com a melhoria do aprendizado dos estudantes. Porém, essa ânsia pela melhor performance e maior produtividade se mostra um indicador claro das pressões externas para fazer esse(a)s professores(as) "sujeitos empresariais", empresas de si mesmos (BALL, 2002).

Neste caso, a autonomia docente em Russas é posta no contexto de inúmeras responsabilidades sem as mínimas condições de realizá-las satisfatoriamente. Para Ruivo (2009, p.35) "Os professores foram treinados para saberem fazer o que sempre fizeram e bem: ensinar. Mas, além disso, todo o dia se lhes exige o cumprimento de cada vez mais objetivos educativos que a sociedade não consegue alcançar”.

\section{Quanto à valorização do trabalho docente: limites e possibilidades do SMAEF}

Em se tratando das informações acerca da valorização do trabalho docente e as contribuições, positivas e negativas, do SMAEF, optamos por categorizar os dados colhidos, uma vez que foram questionamentos subjetivos. Assim, logo abaixo, no quadro 3, temos as categorias encontradas: 
A percepção das professoras e dos professores sobre a avaliação municipal: o caso do SMAEF

Quadro 3 - Implicações do SMEF na Educação Municipal de Russas

\begin{tabular}{|c|c|c|c|}
\hline \multicolumn{2}{|c|}{ Aspectos positivos do SMAEF } & \multicolumn{2}{|c|}{ Aspectos negativos do SMAEF } \\
\hline ASPECTOS & No. RESP. & ASPECTOS & No. RESP. \\
\hline $\begin{array}{lll}\begin{array}{l}\text { Organização } \\
\text { conteúdos }\end{array} & \text { linear } & \text { dos } \\
\end{array}$ & 05 & $\begin{array}{l}\text { Priorização dos componentes } \\
\text { curriculares "Língua Portuguesa" } \\
\text { e "Matemática" }\end{array}$ & 04 \\
\hline $\begin{array}{lll}\begin{array}{l}\text { Aplicação } \\
\text { diagnóstico }\end{array} & \text { com } & \text { cunho } \\
\end{array}$ & 05 & $\begin{array}{lll}\text { Exigências } \\
\text { "resultados" }\end{array}$ & 16 \\
\hline Subjetividade das questões & 01 & Limitação do trabalho docente & 06 \\
\hline O aprendizado da turma & 04 & $\begin{array}{l}\text { Desvalorização dos alunos em } \\
\text { suas particularidades }\end{array}$ & 07 \\
\hline $\begin{array}{l}\text { Familiaridade com provas } \\
\text { externas }\end{array}$ & 11 & Competição entre as escolas & 09 \\
\hline $\begin{array}{l}\text { Preparação para o mercado de } \\
\text { trabalho }\end{array}$ & 02 & Mecanização do ensino & 14 \\
\hline $\begin{array}{l}\text { Não há. (Visão dos } \\
\text { participantes) }\end{array}$ & 13 & Não há. (Visão dos participantes) & 00 \\
\hline Total & 41 respostas & Total & 56 resposta \\
\hline
\end{tabular}

Fonte: autoria própria, 2021, p. 19

Entendendo que muitos foram os aspectos negativos colocados pelos participantes, não esperávamos muitos pontos positivos, o que de fato aconteceu: categorizamos poucos aspectos satisfatórios quando confrontamos a avaliação em questão com as visões docentes.

Respostas como "Se fosse feito de maneira correta, seria verificar a aprendizagem dos alunos e adaptá-los às avaliações externas" (Professor 24). Ou "Boa parte dos estudantes saem preparados para o mercado de trabalho" (Professor 49). Foram algumas das argumentações que encontramos como pontos positivos, mas que, a nosso ver, configuram em aspectos que não ajudam no desenvolvimento pleno dos alunos, pois sua intenção primaz é "a preparação para outras provas externas ou para um suposto mercado de trabalho".

No tocante às categorias construídas a partir das repostas obtidas, assimilamos que quando o colaborador coloca como ponto positivo a "organização linear dos conteúdos" e "aplicação com cunho diagnóstico" ele está se referindo, direto ou indiretamente, à própria proposta curricular que sedimenta o seu trabalho. Dito de outra forma, essa organização é justamente dos conteúdos que, segundo o sistema de ensino municipal, devem ser ministrados nas salas de aulas, figurando-se como preparação para o SMAEF.

Portanto, os aspectos negativos citados revelam-se mais expressivos quando comparados aos aspectos positivos. Partindo de questões inerentes aos componentes curriculares "prestigiados", Língua Portuguesa e Matemática, até pontos mais abrangentes, 


\section{A percepção das professoras e dos professores sobre a avaliação municipal: o caso do SMAEF}

como a mecanização do (sistema) ensino, esses aspectos negativos interferem significativamente todo o processo educacional.

Essas implicações, negativas, subtraem, como exposto no tópico anterior, a autonomia docente, dificultando o processo de ensino (professor) e, por conseguinte, o processo de aprendizagem (aluno), embora nesta relação esses processos se imbriquem, pois não há a valoração das singularidades discentes. Além desse "descuidado" com o alunado no que se refere às singularidades, há também a exacerbada exigência por resultados.

Assim exposto, acerca dos aspectos negativos, identificamos, dentre as respostas, as seguintes argumentações que, sob nossa perspectiva, resume bem a problemática.

Resposta do professor 2:

A gestão acaba priorizando português e matemática, deixando de lado as outras disciplinas, que são tão importantes quanto as cobradas no SMAEF, exigência exagerada por resultados que nem sempre os alunos podem dar, por muitas situações que ele não controla e nem depende dele e do professor; o professor deixa de trabalhar metodologias e conteúdos muito mais importantes no dia a dia dessas crianças, porque é obrigado a dar bons resultados, que para eles têm de ser 10. Motivação, autonomia, educação que faça sentido para as crianças, são desvalorizadas. (Professor 2).

Uma evidência de que esse modelo de avaliação de larga escala acaba gerando um dispositivo controverso de sua criação, pode ser percebida na redução de carga horária nas componentes curriculares que não compõem o rol de exigências neste tipo de exame, tal como, o SMAEF, vejamos o caso da componente curricular Educação Física.

Santos e Gurski (2016) analisaram a diminuição das aulas de Educação Física nas escolas públicas de Curitiba/PR e afirmaram que um possível fator para essa decisão deveuse à forma de reconhecimento de uma disciplina para o currículo escolar e, também, que, para serem consideradas de qualidade, as escolas passam pela avaliação do IDEB, em que se privilegia, principalmente, as disciplinas de Português e Matemática.

Em relato importante de Effgen e Sampaio (2016), ainda acerca da redução de aulas de Educação Física no município de Cascavel/PR. Para os autores, o movimento veio com a reformulação do currículo, que privilegiou as componentes supracitadas. Quando, em 2013, a Secretaria Estadual do Estado do Paraná (SEED) por meio da Instrução SEED/SUED 020/2012, alterou o formato da nova matriz curricular para os anos finais do Ensino Fundamental nas escolas da rede estadual de Educação Básica, e aumentou o número de

RIET- ISSN 2676-0355, Dourados, v. 2, n. 2, p. 368 a 390, jan./jun., 2021 


\section{A percepção das professoras e dos professores sobre a avaliação municipal: o caso do SMAEF}

aulas das disciplinas de Matemática e Português para cinco aulas semanais e deixou apenas 15 aulas para as sete disciplinas restantes ministrarem.

Essa mudança de currículo para privilegiar algumas áreas do conhecimento, em detrimento de outras, não resolve nenhum dos problemas que a escola enfrenta atualmente. $\mathrm{Na}$ prática, torna os/as estudantes mais cansados/as para acessar esses componentes curriculares que assumem um tempo gigantesco no período letivo, como, também, coloca as outras áreas em situação de negar grande parte dos objetos de conhecimento que deveriam ser acessados na escola. As evoluções nos índices das avaliações externas nem sempre melhoram, com essas mudanças (MARTINS, 2020).

Resposta do professor 9:

Acredito que o ensino fica engessado, específico e mecanicista, com um trabalho com foco nos resultados, em notas. A criticidade e a diversidade de demais conhecimentos é deixada de lado e, por vezes, a individualidade de cada sujeito, todos passam a ser números (notas) do sistema e esses que os representam. (professor 9).

Dessa forma, considerando essa avaliação externa, doravante SMAEF, e a pretensão, descontrolada (dos gestores escolar e municipal), de “excelentes resultados”, é público e inegável o acúmulo de trabalhos a serem realizados pelos docentes e "nesse progressivo movimento atribui-se ao professor o título de 'salvador da pátria', pois esse trabalhador é responsabilizado pelo sucesso dos resultados e, com isso, é submetido a condições precárias de trabalho" (DIAS, 2014, p. 11). Esses trabalhos, muitos deles até burocráticos (fichas de acompanhamentos, aplicação e correção de simulados, por exemplo) limitam demasiadamente a práxis desses profissionais.

\section{Considerações finais}

Ao término do que consideramos ser uma audaciosa produção para a comunidade científica, na qual discutimos exaustivamente a percepção das professoras e dos professores acerca das implicações do SMAEF na Educação de Russas, faz-se necessário retomar com clareza as principais contribuições explicitadas ao longo do texto, tendo em vista a relevância histórica que essa temática empreendeu nos últimos anos.

Diante do que foi apresentado, podemos compreender que o trabalho docente naquela região é, por extensão, reflexo da política educacional que implementada no Estado do Ceará, a qual apresenta estreita relação com orientações de organismos internacionais, em

RIET- ISSN 2676-0355, Dourados, v. 2, n. 2, p. 368 a 390, jan./jun., 2021 


\section{A percepção das professoras e dos professores sobre a avaliação municipal: o caso do SMAEF}

que acreditam que o bom desempenho acadêmico seja o principal indicador do sucesso escolar. Nesse sentido, apostam vorazmente em avaliações padronizadas, sem se importarem com os resultados adversos por elas produzidos, como o sentimento de impotência detectado em algumas respostas das professoras e dos professores que não aprovam esta avaliação e os impactos negativos do que aqui denominamos de macropolítica e micropolítica.

Retomando os objetivos traçados neste estudo, podemos dizer que eles foram alcançados com êxito. Ao analisarmos a percepção das professoras e dos professores sobre o SMAEF, percebemos que houve um posicionamento bastante situado de desconfiança na referida avaliação, enquanto mecanismo responsável por avaliar a qualidade da Educação do município. Por hora, a periodicidade com que ocorre o SMAEF o torna mais um instrumento fiscalizador da organização curricular oficial do que uma referência para trabalho docente.

Desse ponto, formulamos uma questão necessária a essa altura: se, como explícito nas Diretrizes do município, o SMAEF é a ferramenta responsável por diagnosticar a qualidade da Educação municipal, quem ou que grupo é responsável por avaliar seus parâmetros? Tendo em vista que são questionáveis e, como já dito, não refletem a realidade do que se passa no município. A quem interessa, efetivamente, o funcionamento do SMAEF da forma como se apresenta?

Embora não saibamos da resposta nesse momento, acreditamos que os professores precisam ser ouvidos nas questões que se referem aos seus alunos e suas alunas. Quais fatores nos levam a acreditar que agentes externos à escola, tido como especialistas, são mais capazes de pensar questões pertinentes à escola do que os próprios professores organizados e articulados com as universidades públicas e a comunidade? É imprescindível essa discussão!

Embora mencionamos que nossos objetivos foram alcançados, reconhecemos que a discussão sobre esta avaliação não se encerra aqui. Por meio deste estudo surgem novas indagações pertinentes aos próximos passos do SMAEF no município investigado. Pensando no contexto pandêmico, o qual modificou as estruturas das escolas brasileiras, resta-nos saber quais os impactos que a pandemia por COVID-19 provocou na Educação de Russas? De que forma afetou o andamento do trabalho docente e aprendizado dos estudantes?

Consideramos um movimento rigoroso sair com essas inquietudes do ponto de vista do perfil investigativo da ciência progressista que mantém vigilância contínua com os fenômenos que se presta a estudar. Estamos caminhando por um caminho empolgante e 


\section{A percepção das professoras e dos professores sobre a avaliação municipal: o caso do SMAEF}

paralelamente angustiante no campo das avaliações externas, pois apontamos nossa lupa para um assunto que as redes de ensino não estão tratando com a devida eficiência com seu corpo docente, e nosso maior intuito foi convidar a classe docente para este debate.

\section{Referências (ABNT)}

AFONSO, Almerindo Janela. Políticas avaliativas e accountability em educação-subsídios para um debate iberoamericano. Sísifo, n. 9, p. 57-70/EN 57-70, 2016.

ANDRÉ, Marli. O que é um estudo de caso qualitativo em educação?. Revista da FAEEBA, v. 22, n. $40,2013$.

BRASIL. Ministério da Educação. Sistema de Avaliação da Educação Básica (SAEB). Disponível em: https://www.gov.br/inep/pt-br/areas-de-atuacao/avaliacao-e-exames-educacionais/saeb. Acesso em: 10 fev. 2021.

CARLOMAGNO, Márcio Cunha. Estudando cultura e comunicação com mídias sociais. Org: SILVA, Tarcízio. BUCKSTEGGE, Jaqueline. ROGEDO, Pedro. Ed. BPAD. Brasília, 2018.

CEARÁ. Secretaria da Educação. Histórico da CREDE 10. 2012. Disponível em:

https://crede10.seduc.ce.gov.br/index.php/institucional/historico. Acesso em: 21 fev. 2021.

CEARÁ. Secretaria da Educação. Sistema Permanente de Avaliação Básica do Ceará (SPAECE). 2018. Disponível em: http://www.spaece.caedufjf.net/o-sistema/o-spaece/. Acesso em: 12 fev. 2021.

CHAVES, Vera Lúcia Jacob. Educação contra a barbárie: por escolas democráticas e pela liberdade de ensinar. Org. Fernando Cássio. 1. Ed. Boitempo. São Paulo, 2019.

CONSELHO NACIONAL DE SAÚDE (Brasil). Resolução $n^{\circ}$ 510, de 7 de abril de 2016. Diário Oficial da União: seção 1, Brasília, DF, n. 98, p. 44, 24 maio 2016. Disponível em: https://pesquisa.in.gov.br/imprensa/jsp/visualiza/index.jsp?jornal=1\&data=24/05/2016\&pagina=44. Acesso em 28 jan. 2021.

COSTA, Fábio Luciano. A mercantilização da educação no Brasil sob a lógica da especulação financeira. FINEDUCA-Revista de Financiamento da Educação, v. 1, 2011.

CUNHA, Niágara Vieira Soares et al. Avaliação externa e autonomia docente: o SMAEF como meio de reprodução da cultura por resultados. movimento-revista de educação, v. 7, n. 15. Disponível em: https://periodicos.uff.br/revistamovimento/article/view/44467/27661. Acesso em: 03 fev. 2021.

DE SOUZA CASTRO, Marilia; DE SOUSA, Eliane Pinheiro. Eficiência dos gastos públicos da rede de ensino municipal cearense. Gestão \& Regionalidade, v. 34, n. 100, 2018.

DIAS, Rubia Mara Ribeiro. Ideb, quantificação e qualidade: avaliação do desempenho no ensino fundamental e os impactos do trabalho docente em escolas de Aguari-MG. Dissertação (Mestrado em Educação). Faculdade de Educação, Universidade Federal do Uberlândia, Minas Gerais, 2014. Disponível em: https://repositorio.ufu.br/handle/123456789/13969. Acesso em: 21 fev. 2021.

RIET- ISSN 2676-0355, Dourados, v. 2, n. 2, p. 368 a 390, jan./jun., 2021 


\section{A percepção das professoras e dos professores sobre a avaliação municipal: o caso do SMAEF}

EFFGE, Deliane Paula; SAMPAIO, Adelar Aparecido. Implicações no processo pedagógico pela redução de aulas de educação física. Os desafios da escola pública paranaense na perspectiva do professor PDE. Cadernos PDE, 2016.

FREIRE, Paulo. Pedagogia do oprimido. Rio de Janeiro: Paz e Terra, 2013.

HOFFMANN, Jussara Maria Lerch. Avaliação mediadora: uma prática em construção da préescola à universidade. Porto Alegre: Editora Mediação, 2003.

HOFFMANN, Jussara Maria Lerch. Avaliação mediadora: uma relação dialógica na construção do conhecimento. Avaliação do rendimento escolar. São Paulo: FDE, p. 51-9, 1994.

HUBERMAN, Michael. O ciclo de vida profissional dos professores. In: NÓVOA, António. Vida de professores. Porto Alegre, Porto Editora, 1995.

IBGE. Cidades e Estados: Russas. Rio de Janeiro: IBGE, 2020. Disponível em: https:// https://www.ibge.gov.br/cidades-e-estados/ce/russas.html. Acesso em: 02 fev. 2020.

LEHER, Roberto. Um novo senhor da educação? A política educacional do Banco Mundial para a periferia do capitalismo. Outubro, v. 1, n. 3, p. 19-30, 1999.

LIMA, Alessio Costa. Ciclo de avaliação da educação básica do Ceará: principais resultados. Estudos em Avaliação Educacional, v. 23, n. 53, p. 38-58, 2012.

LUCKESI, Cipriano. Avaliação escolar: estudos e preposições. São Paulo: Cortez, 1996.

MACHADO, Mikeully Meire de Andrade. Responsabilização (accountability), gestão por resultados, rotina escolar e perda da autonomia profissional dos docentes do município de Russas - CE. 2019. Dissertação (Mestrado Acadêmico Intercampi em Educação e Ensino) Universidade Estadual do Ceará, Fortaleza, 2019.

MARTINS, Raphaell Moreira. Caminhos e descaminhos do currículo da Educação Física no IFCE, campus Itapipoca. PINTO, Nilson Vieira; LIMA, Patrícia Ribeiro Feitosa; MARTINS, Raphaell Moreira. Transfazeres do ensino na educação profissional e tecnológica. Fortaleza: INESP, 2020.

MEIRINHOS, Manuel; OSÓRIO, António. O estudo de caso como estratégia de investigação em educação. Eduser - Revista de Educação, [S.1.], v. 2, n. 2, dec. 2016. ISSN 1645-4774.

Disponível em: https://www.eduser.ipb.pt/index.php/eduser/article/view/24. Acesso em: 18 feb. 2021. DOI https://dx.doi.org/10.34620/eduser.v2i2.24.

MINAYO, Maria Cecília. Pesquisa social: teoria, método e criatividade. 21 ed. Editora Vozes. Petrópolis, 2002.

MORAES, Roque. Análise de conteúdo. Revista Educação, Porto Alegre, v. 22, n. 37, p. 7-32, 1999.

NOSELLA, Paolo. A atual política para a educação no Brasil: a escola e a cultura do desempenho. Revista Faz Ciência, v. 12, n. 16, p. 37, 2010.

ROSSATO, Maristela; MATOS, Jonas Filippe; PAULA, Ribanna Martins de. A subjetividade do professor e sua expressão nas ações e relações pedagógicas. Educação em Revista, v. 34, 2018.

RIET- ISSN 2676-0355, Dourados, v. 2, n. 2, p. 368 a 390, jan./jun., 2021 


\section{A percepção das professoras e dos professores sobre a avaliação municipal: o caso do SMAEF}

RUIVO, João. Formação, avaliação e autonomia docente. Avaliação de Desempenho de Professores, p. 35, 2009.

RUSSAS. Secretaria Municipal da Educação e do Desporto Escolar. Diretrizes da Educação Municipal 2017-2020. Russas: SEMED, 2017.

RUSSAS. Secretaria Municipal da Educação e do Desporto Escolar. IDEB 2017: Desempenho de Russas supera médias do Ceará e Brasil. Prefeitura Municipal de Russas, Russas, 2019. Disponível em: https://russas.ce.gov.br/destaque/ideb-2017-educacao-de-russas-de-parabensdesempenho-do-municipio-supera-medias-do-ceara-e-brasil/. Acesso em: 21 fev. 2021

RUSSAS. Secretaria Municipal da Educação e do Desporto Escolar. Plano Municipal de Educação: Russas - Ceará: 2015-2025. Russas: SEMED, 2015.

SANTANA, Andréia da Cunha Malheiros. A constituição do Estado Avaliativo e o aumento das avaliações externas: propagando um ensino desigual para todos. Avaliação da educação, p. 37, 2018.

SANTOS, Elieser dos; GURSKI, Luciano de Lacerda. A diminuição de aulas de educação física nas escolas públicas de Curitiba de ensino fundamental anos finais. XI EVINCI - Anais [...], v. 2 n. 1: Caderno de Resumos, 2016.

VOSS, Dulce Mari Silva; GARCIA, Maria Manuela Alves. O discurso da qualidade da educação e o governo da conduta docente. Educação \& Realidade, v. 39, n. 2, p. 391-412, 2014.

RIET- ISSN 2676-0355, Dourados, v. 2, n. 2, p. 368 a 390, jan./jun., 2021 